\title{
Neuropsychological and Educational Profile of Children with Dyscalculia and Dyslexia: A Comparative Study
}

\author{
Magda Solange Vanzo Pestun ${ }^{1}$ \\ Rauni Jandé Roama-Alves ${ }^{2}$ \\ Sylvia Maria Ciasca ${ }^{3}$ \\ ${ }^{1}$ Universidade Estadual de Londrina, Londrina, PR \\ ${ }^{2}$ Universidade Federal de Rondonópolis, Rondonópolis, $M T$ \\ ${ }^{3}$ Universidade Estadual de Campinas, Campinas, SP
}

\begin{abstract}
This paper aims to compare the neuropsychological and educational profiles of Brazilian children with dyscalculia $(\mathrm{n}=8)$, dyslexia $(n=13)$ and without learning disabilities $(n=12)$. The neuropsychological profile was composed of: (a) intelligence assessed by the Wechsler Intelligence Scale for Children (WISC-III); (b) attention - WISC-III Coding and Symbol Search subtests; (c) executive functions - Digit Span (backward order) and WISC-III Arithmetic subtests, Pseudoword Repetition Test for Brazilian Children, Stroop Test and Wisconsin Card Sorting Test; (d) memory - WISC-III Digit Span subtest (forward order) and Rey Complex Figures. The educational profile was composed of reading, writing and mathematics, assessed by the Academic Performance Test and the Arithmetic Test. It was found that the groups with dyscalculia and dyslexia did not differentiate in any of the neuropsychological abilities, only in the reading and writing abilities. Neuropsychological variables that could explain these results were discussed.

Keywords: Assessment. Arithmetic. Learning disorders.
\end{abstract}

\section{Perfil Neuropsicológico e Escolar de Crianças com Discalculia e Dislexia: Estudo Comparativo}

\begin{abstract}
Resumo
Objetivou-se comparar os perfis neuropsicológico e escolar de crianças brasileiras com discalculia $(n=8)$, dislexia $(n=13)$ e sem dificuldades escolares $(n=12)$. O perfil neuropsicológico foi composto por: (a) inteligência: avaliada pela Escala de Inteligência Wechsler para Crianças (WISC-III); (b) atenção: subtestes Códigos e Procurar Símbolos da WISC-III; (c) funções executivas: subtestes Dígitos (ordem inversa) e Aritmética da WISC-III, Teste de Repetição de Pseudopalavras para Crianças Brasileiras, Teste de Stroop e Teste Wisconsin de Classificação de Cartas; (d) memória: subteste Dígitos (ordem direta) da WISC-III e Figuras Complexas de Rey. O perfil escolar foi composto por leitura, escrita e matemática, avaliado pelo Teste de Desempenho Escolar e pela Prova de Aritmética. Verificou-se que os grupos com discalculia e com dislexia não se diferenciaram em nenhuma das habilidades neuropsicológicas, somente nas habilidades escolares de leitura e escrita. Variáveis neuropsicológicas que pudessem explicar esses desempenhos intergrupos foram discutidas.

Palavras-chave: avaliação, aritmética, transtornos de aprendizagem
\end{abstract}

\section{Perfil Neuropsicológico y Educativo de los Niños con Discalculia y Dislexia: Estudio Comparativo}

\begin{abstract}
Resumen
El objetivo de este trabajo fue comparar los perfiles neuropsicológicos y escolares de niños brasileños con Discalculia ( $\mathrm{n}=$ 8), Dislexia $(n=13)$ y niños sin dificultades escolares $(n=12)$. El perfil neuropsicológico fue compuesto por: (a) inteligencia: evaluada por Escala de Inteligencia Wechsler para Niños (WISC-III); (b) atención: subtests Códigos y Búsqueda de Símbolos de la WISC-III; (c) funciones ejecutivas: subtests Dígitos (orden inverso) y Aritmética de la WISC-III, Test de Repetición de Pseudopalabras para Niños Brasileños, Test de Stroop y Test Wisconsin de Clasificación de Cartas; (d) memoria: subtest Dígitos (orden directo) de la WISC-III y Figuras Complejas de Rey. El perfil escolar fue compuesto por lectura, escritura y matemática, evaluado por el Test de Desempeño Escolar y por la Prueba de Aritmética. Se verificó que los grupos con Discalculia y con Dislexia no se diferenciaron en ninguna de las habilidades neuropsicológicas, sólo en las habilidades escolares de lectura y escritura. Fueron discutidas variables neuropsicológicas que pueden explicar esos desempeños intergrupales. Palabras clave: Evaluación, Aritmética, Trastornos de aprendizaje.
\end{abstract}

According to the Diagnostic and Statistical Manual of Mental Disorders (DSM-V), Specific Learning Disorders (SLD) are a type of neurodevelopmental disorders. They are characterized by specific deficits in the individual's ability to perceive or process academic information efficiently and accurately, despite adequate schooling and intelligence within or above normality. It occurs during years of formal schooling, through persistent and harmful difficulties in basic reading, writing and / or math skills. 
Among the SLD, there is developmental dyslexia, an alternative term for the disorder that affects learning, specifically reading, and developmental dyscalculia, an alternative term for the disorder that affects mathematics learning (APA, 2013). According to neuropsychological theories and findings, certain impairments in some specific cognitive abilities would be responsible for these disorders. Regarding dyslexia, one may cite: (a) the phonological deficit: assumes major losses in the phonological processing of information, which would be the basis of reading, and involve left perisylvian zones (Ramus, Marshall, Rosen, \& van der Lely, 2013); (b) cerebellar disorders: these losses would cause specific changes in language and consequently in reading (Nicolson \& Fawcett, 2011); (c) magnocellular theory: impairments in this cerebral pathway, which is related to visual processing, perception of figureground contrast and movement, would collaterally affect the sound decoding of graphemes (Jednoróg, Marchewka, Tacikowski, Heim \& Grabowska, 2011).

Findings and theories on dyscalculia have also been elaborated, among them one can cite: (a) the theory of the double system: there would be losses in one or both systems responsible for the arithmetic reasoning - one of them would be responsible for the visual processing of numbers and the other for the verbal component of numbers (the way one speaks and writes) (McCloskey, Caramazza, \& Basili, 1985); (b) hemispherical processing: each hemisphere would be responsible for the processing of certain abilities, the right for numerical conceptualization (recognition and production of symbols) and spatial orientation, and the left for operational and mental calculations, numerical sequence recognition, right-left orientation; losses in processing these abilities in one or both hemispheres could cause the disorder (O'hare, Brown, \& Aitken, 1991); (c) triple-code model: there could be losses in inferior occipito-temporal zones of both hemispheres, responsible for the meaning of numbers; and / or losses in the left perisylvian zone, responsible for verbal representation of numbers; and / or losses, also in the inferior parietal zones of both hemispheres responsible for quantitative analog representations (Stanescu-Cosson et al., 2000).

In addition, deficits in other neuropsychological abilities may secondarily track these major impairments, such as attention, Executive Functions (EF) and memory, both in dyslexia (Bogaerts, Szmalec, Page, \& Duyck, 2014; Menghini et al., 2010; Ziegler, PechGeorgel, Dufau, \& Grainger, 2010) and in dyscalculia
(Ashkenazi, Rubinsten, \& Henik, 2009; Attout, Salmon \& Majerus, 2015)

Interestingly, Wang, Tasi and Yang (2012) sought to compare inhibitory control, a classic ability among EF, among such disorders. The results indicated statistically significant differences among them, in tasks involving numeric and verbal stimuli (as in the Stroop Test), with inferior performances in the first tasks of those who had dyscalculia and inferior performances in other tasks of those who had dyslexia. On the other hand, Landerl, Fussenegger, Moll and Willburger (2009) sought to identify possible differences in measures of auditory operating memory (repetition of digits and non-words) and visual operational memory (Corsi Cubes). However, the results indicated similar intergroup data, with more similarities being found than differences among them. Unfortunately, in a brief search of Brazilian articles, no studies with similar design were found. The descriptors "dyslexia", "dyscalculia", "memory", "executive functions", "attention", "reading", "writing" and "mathematics" were used for this purpose, "and" being used between the descriptors as boolean operator, in Scielo databases and Brazilian Digital Library of Theses and Dissertations.

On the other hand, intragroup comparison studies of the school skill profile are more frequently observed in literature. Many have shown, for example, that a lagged arithmetic performance in dyslexia is common (Boets \& Smedt, 2010; Caldonazzo, Salgado, Capellini \& Ciasca, 2006; Geary, Hoard, Nugent \& Bailey, 2012; Träff \& Passolunghi, 2015). Likewise, there has also been a discrepancy in the reading and writing processes in dyscalculia (Shalev, Manor, \& Gross-Tsur, 2005; Wilson \& Dehaene, 2007).

Therefore, it is asked: what would be the performance profile of both disorders which would differentiate them in more detail? Diagnostic criteria generally establish that the main impairment in dyslexia is reading learning and in dyscalculia is mathematics, but they also allow additional difficulties to be present, such as math in the first disorder and reading in the second, as well as in several, often similar, neuropsychological abilities, in both cases (APA, 2013). According to what is commonly seen in clinical practice, it was raised as a hypothesis that the school and neuropsychological abilities could differ when the evaluative stimuli and their constructs evaluated were involving the most characteristic impairments of each condition. For example, in instruments with mathematical stimuli, statistically lower performances should be found in the group with 
dyscalculia when compared to the group with dyslexia. Likewise, reading skills should be significantly lower in the group with dyslexia when compared to the group with dyscalculia.

In order to investigate this hypothesis empirically, this study aimed to compare the neuropsychological and educational profiles of children with developmental dyscalculia and developmental dyslexia. Specifically, the neuropsychological profile was composed by intelligence, attention, executive functions (working memory (phonological loop), inhibitory control and thought flexibility) and memory; and the educational profile for reading, writing and mathematics. A group without complaints related to learning difficulties was also introduced in intergroup comparison analyzes, in order to investigate, in detail, the profiles when compared to non-nosological groups.

\section{Method}

\section{Participants}

The total sample consisted of 33 children, divided into three groups:

a) Non-Case Group (NCG): 12 participants without complaints of school difficulties, mean age of 9.65 years $(\mathrm{SD}=0.94)$, six of them male, and belonging to the third $(\mathrm{n}=4)$ to the fourth $(\mathrm{n}=8)$ grade of school, most of them $(n=8)$ from public schools.

b) Developmental Dyscalculia (DD): eight participants, mean age of 10.37 years $(S D=0.91)$, five of them female, and belonging to the third ( $\mathrm{n}=$ $2)$, fourth ( $n=1)$ and fifth $(n=5)$ grade of school, most of them from ( $\mathrm{n}=7$ ) public schools; without comorbidities with other neurodevelopmental disorders.

c) Developmental Dyslexia: 13 participants, mean age of 10.15 years $(\mathrm{SD}=1.27)$, eight of them males, and belonging to the third $(n=5)$, fourth $(n=4)$ and fifth $(n=4)$ grade of school, most of them ( $n$ = 11) from public schools; without comorbidities with other neurodevelopmental disorders.

The inferential statistics did not show significant differences among the three groups in gender (chisquare test, $\left.\chi^{2}=1.163, \mathrm{p}=0.559\right)$, age (Kruskal-Wallis test, $\chi^{2}=2.050, \mathrm{p}=0.359$ ) and school type (public or private) (Fisher's exact test, $\mathrm{p}=0.558$ ). There was only a significant difference among the three groups regarding schooling (Fisher's exact test, $\mathrm{p}=0.036$ ). However, when comparing groups of two, only NCG and DD were found to differ (Fisher's exact test, $p=0.004$ ). It should be noted that the control of age, gender and school type was paramount in this study, when matching the three groups, which did not occur on schooling. The first three variables usually have a stronger impact on the performance profile in Specific Learning Disorders, while the grade of school is common to be discrepant among the ages in these cases (APA, 2013). Thus, the research was continued even with the differences found, not configuring, for example, "having schooling compatible with age" as a criterion for group inclusion. In fact, children with educational level without major variations were included, the range adopted was from the third to the fifth grade, as it is shown in the next paragraph.

For all groups, the inclusion criteria were: not having serious illness, genetic syndromes and not being in drug treatment, according to parents / guardians; and to be a student in the third to fifth grade of elementary school, according to parents / guardians and / or teachers. For the groups with dyslexia and dyscalculia there were also the criteria that: children should have been evaluated and diagnosed by the extension project "Learning disorders: diagnosis and intervention" of the Psychology course at the Universidade Estadual de Londrina, and do not show comorbidities with other neurodevelopmental disorders; they should not have made interventions on their difficulties (other than "school reinforcement") according to parents / guardians. In addition, for NCG there were also the following criteria: not showing complaints of school difficulties and sensory deficiencies, according to parents / guardians and teachers; and have no intellectual disability. The only exclusion criterion adopted was the withdrawal of the children's participation (for their own or parents' / guardians' sake) throughout all the research procedures.

\section{Instruments}

Anamnesis interview script with parents / guardians (prepared by the authors themselves). Script composed of questions that aimed at the collection of complaints and information about the child's development. The main data of interest for analysis were: neuropsychomotor development, feeding, sleep, schooling, health conditions and social skills.

Questionnaire for teachers (prepared by the authors). Composed of objective questions that sought to collect information about the child's school performance, 
level of comprehension, interest, reading, writing and arithmetic skills.

\section{Intelligence Assessment}

Wechsler Intelligence Scale for Children (WISC-III) (Figueiredo, 2002). Instrument validated for the Brazilian population. Individual application that evaluates the intellectual capacity of children aged between six and 16 years old and 11 months. It is composed of 13 subtests, six verbal and seven execution subtests. The results of these subtests can be grouped in: Verbal IQ (VIQ), performance IQ (PIQ) and total IQ (TIQ); and also in four Factorial Indexes: Verbal Reasoning (CR), composed of subtests Information, Similarities, Vocabulary and Understanding), Perceptual Organization (POI); Completing Figures, Arrangement of Figures, Cubes and Assembling Objects subtests), Resistance to Distraction (RDI; Arithmetic and Digit Span subtests) and Processing Speed (PSI; Coding and Symbol Search subtests).

Among the numerous psychometric studies performed for this instrument, one can highlight the convergent validity studies, which were performed with Raven's Colored Progressive Matrices test $(r=0.77)$ and with school grades $(r=0.47)$. Their reliability was also investigated through the verification of temporal stability (test-retest). The subtests Coding and Symbol Search were specifically investigated, for which correlations considered adequate were found, with the values of 0.70 and 0.63 , respectively (Figueiredo, 2002).

\section{Attention Assessment}

WISC-III Coding Subtests and Symbol Search (Figueiredo, 2002). The Coding subtest consists of the task of associating symbols with numbers as quickly as possible, in writing. It classically targets the evaluation of selective attention. The Symbol Search subtest consists of a task in which who is evaluated must visually analyze a particular model symbol and look for it in a set of others, indicating whether it is present or not. It evaluates the ability of concentrated attention.

\section{Assessment of Executive Functions}

WISC-III Digit Span Subtests (backward order) and Arithmetic (Figueiredo, 2002). The backward digit span subtest is composed of the presentation of some orally numeric sequences in which who is evaluated should repeat from back to front. It is taken as a measure of working memory (phonological loop). The Arithmetic subtest is composed by the mental resolution of arithmetic problems. It evaluates the manipulation of numerical information, concentration, short and longterm memory.

Pseudoword repetition test for Brazilian children (PRBC) (Santos \& Bueno, 2003). This test, validated for the Brazilian population, evaluates the operational memory (phonological loop) and demands phonological patterns recognition skills that are part of the Brazilian Portuguese through 40 pseudowords. The respondent is asked to repeat immediately the pseudowords spoken by the examiner, just as he/she heard them. Each correct answer corresponds to one point.

Univariate Analysis of Variance (ANOVA) was performed and age effect was found $(\mathrm{F}(6.175)=10.22$, $\mathrm{p} \leq 0.001)$. Length effect $(\mathrm{F}(3.525)=90.1, \mathrm{p} \leq 0.0001)$ and interaction between age and length $(\mathrm{F}(18.525)=$ 3.87, $\mathrm{p}<0.0001)$ were observed. When the Covariance Analysis was performed, the age effect disappeared ( $F$ $(6,173)=1.32, \mathrm{p}=0.24)$, as length effect $(\mathrm{F}(3,522)=$ $90.8, \mathrm{p} \leq 0.0001)$ and age-length interaction $(\mathrm{F}(18.522)$ $=3.86, \mathrm{p} \leq 0.0001)$ remained. The reliability study showed internal consistency of $0.81(\mathrm{p} \leq 0.01)$ (Santos \& Bueno, 2003).

Stroop test (Duncan, 2006). Classically used as a measure of inhibitory control (intentional control over the tendency to give an impulsive response). It consists of three distinct cards: (1) with colored rectangles; (2) color names written in length and colored with the colors that represent it; (3) color names written in length and not colored with the colors that represent them. The three cards are administered separately, and the instruction is always the same: say the name of the colors, from left to right and from top to bottom. The data of interest for analysis were the time, in seconds, and the number of wrong answers on each card. The time limit for each card was 45 seconds.

According to the psychometric data obtained for the test, when the time variable was analyzed through the Multivariate Analysis of Variance (MANOVA), it was observed that the type of school (public or private) $(\mathrm{F}=15,16, \mathrm{p} \leq 0.0001)$ and age $(\mathrm{F}=2.43, \mathrm{p}=$ $0.0269)$ showed a highly significant effect, unlike sex, which had no significant effect $(\mathrm{F}=1.64, \mathrm{p}=0.1833)$ (Duncan, 2006).

Wisconsin Card Sorting Test (WCST) (Cunha et al., 2005). It evaluates the ability to reason abstractly and to modify cognitive strategies in response to environmental changes, largely checking for flexibility of thinking. The WCST consists of four stimulus cards and 128 response cards, representing figures of various 
shapes (crosses, circles, triangles or stars), colors (red, blue, yellow or green) and numbers (two, three or four). It provides number measures of completed categories, the total of correct responses and errors, total perseverative / non-perseverative errors, total perseverative responses, number of attempts until completing the first category of 10 correct responses, failure to maintaining the initial goal, and score "learning to learn" (increased effectiveness in completing the category of 10 correct responses throughout the test).

The psychometric studies indicated data related to reliability with generalizability coefficients varying from 0.37 to 0.72 . Validity studies indicated that the test was able to identify children with attention deficit disorder and hyperactivity. The influence of schooling and sex was investigated by means of ANOVA, being found only effect of the first $(F=10.377 ; \mathrm{p} \leq 0.01)$ and there was no interaction between them (Cunha et al., 2005).

\section{Memory Assessment}

WISC-III Digit Span subtest (forward order) (Figueiredo, 2002). It consists of the oral presentation of a series of numerical sequences in which the examiner must repeat them. It aims to evaluate the short-term auditory memory.

Rey Complex Figures (RCF) (Oliveira \& Rigoni, 2010). It aims to evaluate short-term visual memory. The test has two parts, and in the first one who is evaluated is asked to copy a complex and abstract geometric figure and, in the second, to reproduce this figure from memory. The percentile is obtained for both copy and memory reproduction as well as for the time of both conditions.

Internal consistency was shown, using Cronbach's alpha coefficient, 0.86 in the copy variable and 0.81 in memory reproduction. For evidence of convergent validity, the RCF was correlated with some WISC-III subtests. The copy variable presented a correlation of $0.37(\mathrm{p} \leq 0.001)$ with the Arithmetic subtest and $0.38(\mathrm{p} \leq 0.001)$ with the Digit Span subtest. The memory reproduction variable showed a correlation of $0.33(\mathrm{p} \leq 0.001)$ with the Arithmetic subtest and of $0.24(\mathrm{p}<0.02)$ with the Digit span subtest (Oliveira \& Rigoni, 2010).

\section{Assessment of Educational Skills}

School Achievement Test (SAT) (Stein, 1994). Instrument validated for the Brazilian population, destined for children from $1^{\text {st }}$ to $7^{\text {th }}$ grade of elementary school. It aims to assess basic school skills. It consists of three subtests: Reading, Writing and Arithmetic. The first one consists of 70 familiar words with increasing degree of complexity and size. The second by writing the proper name and by 34 familiar words that are dictated by the examiner one by one. The arithmetic subtest consists of an oral part (three problems presented by the examiner and answered by the respondent, orally) and another written, consisting of 35 arithmetic operations with increasing degree of complexity.

Evidences of validity, through MANOVA, showed that there was discrimination between school year and types of school, having as dependent variables the scores in the three subtests and as independent to school year $\left(2^{\text {nd }}\right.$ to $7^{\text {th }}$ grade). Large differences were found between school year by the total score of each subtest $(\mathrm{p} \leq 0.001)$. The internal consistency analysis showed the following precision values: writing subtest with $\alpha=0.958$, arithmetic with $\alpha=0.836$ and reading with $\alpha=0.958$ (Stein, 1994).

Arithmetic Test (Capovilla, Montiel \& Capovilla, 2007). Test in validation process. It can be applied to $2^{\text {nd }}$ to $5^{\text {th }}$ grade students of elementary school and aims to evaluate the arithmetic abilities of: writing in length of numbers shown algebraically and orally; writing of numerical sequences, increasing and decreasing; comparison of numerical magnitude; calculation of arithmetic operations shown in writing and orally; and solving written mathematical problems. It is composed of 60 questions, each one worth a point.

In validity evidence analyzes, a school year effect was identified through ANOVA, with results that showed a significant improvement in performance as the development of this variable occurred $(F(7,586)=$ $339,82, \mathrm{p} \leq 0.001)$. Specifically, in research on validity evidence based on the internal structure, by means of exploratory factor analysis, in younger children, from the $2^{\text {nd }}$ to the $5^{\text {th }}$ grade, only one factor (arithmetic competence) was found, from the $6^{\text {th }}$ to the $9^{\text {th }}$ grade, two, called numerical processing and calculation. These data are compatible with the literature in this regard (Seabra, Dias \& Macedo, 2010).

\section{Procedure}

Firstly, the children who belonged to DD and developmental dyslexia were recruited in the extension-program project "Learning disorders: diagnosis and intervention". This project is composed of students from the Psychology course at the Universidade Estadual de Londrina, who carry out the services, and a coordinating / supervising teacher. In this project, 
neuropsychological assessments are performed that result in psychological diagnoses, such as those sought for research in this research. About eight to ten sessions are performed to achieve these objectives, based on a descriptive / understanding neuropsychological model, with qualitative and quantitative analyzes. Thus, some of the tests that would make up this research were already part of the protocol of their services (WISCIII, PRTBC, RCF and SAT).

At the time of the research, the project coordinator selected children who had been identified with DD $(\mathrm{n}=8)$ and dyslexia $(\mathrm{n}=13)$ during in the last month and called their parents / guardians to a meeting (which lasted an average of 50 minutes). At that meeting, the research was presented and requested authorization for the application of other instruments that did not belong to the protocol (Stroop Test, WCST and Arithmetic Test), as well as for the use of the data obtained during the diagnostic process. All of them accepted the participation, being required to read and sign the Free Prior and Informed Consent (FPIC). Next, the script of "Anamnesis interview with parents / guardians" was administered focusing on the investigation of the inclusion criteria. All children called were included. The management of these new tests in these children was carried out in an average of two sessions of 50 minutes, in the psychological clinic at the Universidade Estadual de Londrina.

The NCG, in turn, was recruited in a school that met students from the school years included in the inclusion criteria (from the third to the fifth grade). After choosing one, randomly selected, authorization was requested to carry out the research. After authorization granted by the school management and in an initial visit, the objectives of the research were presented to some teachers and requested their participation. All the teachers invited accepted, and afterwards the reading and signing of the "FPIC for Teachers" was requested. The role of these professionals was to select some students, at their convenience, and to respond to the "Questionnaire for teachers" regarding such children. The criteria of "being a student in the third to fifth grade of elementary school" and "not showing complaints of school difficulties and sensory impairments" were investigated in detail. All children indicated by them were included, a total of 12 .

Then, the parents / guardians of these children were called to a meeting (which lasted an average of 50 minutes). At this meeting, the research was presented and asked for authorization to evaluate their children. All of them accepted, being asked to read and sign the FPIC. Then, the script of "Anamnesis interview with parents / guardians" was administered aiming to investigate practically all inclusion criteria, not just the "presence of intellectual disability". On days settled with the school administrators, data collection was started, held in the school, in classrooms assigned and prepared for this purpose. In total, for the application of all the tests, an average time of six sessions of 50 minutes was used. After this procedure, the instruments were corrected and, in order to verify the criterion of "not presenting intellectual disability", the WISC-III result was used, selecting only the children with medium or above average performance in this instrument. It is noteworthy that all children assessed were included.

At the end of all evaluation processes, a devolution session was held for all parents / guardians, with a report composed of the results. Specifically, for the children belonging to DD and developmental dyslexia, the importance of performing interventions at multi / interdisciplinary level was reinforced. Related to the NCG, the difficulties and facilities of each children were indicated, and orientations were made so that each one of these aspects was stimulated.

The SPSS Statistics 20.0 program for Windows ${ }^{\circledR}$ (SPSS Inc, Chicago, IL, USA, 2008) was used to analyze the data. By means of the descriptive statistics, frequency, average, standard deviation, minimum and maximum score data were obtained. Given the size of the sample and, consequently, absence of normal distribution, the types of inferential statistics analysis selected were all non-parametric. All of the aforementioned procedures were authorized by the Research Ethics Committee (CAAE: 3111114714.2.0000.5231).

\section{Results}

In Table 1, data regarding intelligence assessment of the three groups, performed through the WISCIII, can be verified. The gross scores and ratings obtained are shown. Specifically, through the analysis of gross scores, significant differences were observed among the three groups in RDI and PSI. On the other hand, when the groups were compared two by two, it was verified that the NCG showed higher scores than the DD, statistically significant, only in the PSI. When compared to developmental dyslexia, differences were observed in PSI, VIQ, CR and RDI, with significantly higher NCG scores. Statistically significant differences 
between DD and developmental dyslexia were not observed.

Regarding the instruments selected for attention assessment, when comparing the gross scores obtained by the three groups in both subtests (Coding and Symbol Search), significant differences were found between them. When comparing groups two by two, NCG scores were significantly higher in relation to DD, in both subtests. In the same way, this result occurred in relation to the developmental dyslexia. However, when comparing the DD and developmental dyslexia groups, again no significant differences were found between them in both subtests (Table 2).

In Table 2 it is also possible to observe the EF data. When comparing the gross scores obtained in the Digit span subtest (backward order) among the three groups, no significant differences were verified among them, and this also happens when the groups were compared two by two. In the Arithmetic subtest, this same result is observed. In the PRBC test, no significant differences were found among the three groups. However, when comparing groups two by two, there was a significant difference between NCG and developmental dyslexia, with higher NCG scores. In the Stroop test, significant differences were observed among the three groups only in time needed to name the first card colors. In the comparison of groups two by two, only one difference between groups was found, which was between NCG and developmental dyslexia and in the comparison of this same variable of the test, with shorter times obtained by NCG, that is, superior performances of this group.

Regarding the WCST test, when comparing the scores obtained by the three groups, no significant differences were observed in any of the measures evaluated. When comparing groups two by two, significant differences were identified only in the category of 'failure to maintaining the context' between NCG and developmental dyslexia, with higher NCG performances. Thus, there were no significant differences between the DD and developmental dyslexia groups in the instruments used for EF assessment.

Still in Table 2, the data related to memory assessment are observed. In the Digit Span subtest (forward order) there was a significant difference among the three groups when compared at once. In the comparison of groups two by two, statistically significant higher NCG scores were verified when compared to DD and developmental dyslexia. No difference between DD and developmental dyslexia. When comparing the three groups in the RCF test, no significant differences were found among them, it was the same case when groups two by two were compared.

Finally, Table 3 shows the data obtained in the instruments selected for the evaluation of educational skills. It was initially verified in the APT that when comparing the three groups there were statistically significant differences among them in the Reading and Writing subtests and in the total of that test. When comparing groups two by two, it was verified that there was no significant difference between NCG and DD in any of the subtests, nor in the total. On the other hand, there was significant difference between the NCG and developmental dyslexia groups in Reading, Writing and Total, with the first showing higher scores. Between the groups with DD and developmental dyslexia, the same pattern of differences was observed, with DD showing higher scores. In the Arithmetic Test there were no significant differences among the three groups. When comparing groups two by two, no significant differences were found between any of the groups.

\section{Discussion}

In the intelligence assessment, no differences were observed among the groups in the TIQ, which indicates a certain intragroup homogeneity. These results were expected, since children with Specific Learning Disorders do not have performance deficits in this variable (APA, 2013). The differences found among the groups in the PSI and RDI will be discussed in detail when attention, memory and executive functions are addressed, since the subtests that comprise them were part of the assessment of such abilities. The lower performance in the VIQ and CR found in the group with dyslexia, when compared to the non-case group, was in agreement with some studies that also pointed out such differences, probably due to the linguistic impairment, characteristic of the picture in question (Lima, Azoni, \& Ciasca, 2013; Moura, Simões, \& Pereira, 2014). Differences between the groups with dyslexia and dyscalculia were not observed and no study was found that indicated similar or discrepant results in these categories.

In the Attention assessment, there was inferior performance of both the groups with dyscalculia and dyslexia when compared to the non-case group. These findings meet national and international literature, which showed impairments in this ability, in these disorders, when compared to groups of individuals without school difficulties (Ashkenazi et al., 2009; Ziegler et 
Table 1.

Performances and comparisons between groups obtained through the WISC-III

\begin{tabular}{|c|c|c|c|c|c|c|c|}
\hline \multirow{4}{*}{ WISC-III } & \multicolumn{6}{|c|}{ Groups } & \multirow{4}{*}{ Mann-Whitney } \\
\hline & \multicolumn{2}{|c|}{ DD } & \multicolumn{2}{|c|}{ DYSLEXIA } & \multicolumn{2}{|c|}{ NCG } & \\
\hline & \multicolumn{6}{|c|}{ Gross Scores } & \\
\hline & $\mathbf{M}$ & SD & $\mathbf{M}$ & SD & $\mathbf{M}$ & SD & \\
\hline VIQ & 83.87 & 17.43 & 76.84 & 14.01 & 94.08 & 19.80 & NCG > DYSLEXIA* \\
\hline PIQ & 146.62 & 33.00 & 135.76 & 32.87 & 164.75 & 37.25 & - \\
\hline TIQ & 230.50 & 48.21 & 212.61 & 41.25 & 252.83 & 52.18 & - \\
\hline CR & 60.75 & 15.07 & 54.84 & 11.91 & 69.08 & 18.72 & NCG > DYSLEXIA* \\
\hline POI & 93.37 & 23.69 & 84.38 & 28.47 & 92.25 & 33.42 & - \\
\hline RDI a,* & 23.12 & 3.56 & 22.61 & 3.15 & 26.83 & 4.15 & NCG > DYSLEXIA* \\
\hline \multirow[t]{4}{*}{ PSI a,* } & 53.25 & 10.22 & 51.38 & 11.98 & 67.41 & 14.58 & $\mathrm{NCG}>\mathrm{DD} *$ \\
\hline & & & & & & & NCG > DYSLEXIA** \\
\hline & \multicolumn{7}{|c|}{ DD Classification - $f(\%)$} \\
\hline & VS & SP & HA & AV & LA & BL & EL \\
\hline VIQ & $0(0)$ & $0(0)$ & $2(25)$ & $5(62)$ & $1(12)$ & $0(0)$ & $0(0)$ \\
\hline PIQ & $0(0)$ & $0(0)$ & $4(50)$ & $4(50)$ & $0(0)$ & $1(7)$ & $0(0)$ \\
\hline TIQ & $0(0)$ & $1(12)$ & $2(25)$ & $5(62)$ & $0(0)$ & $0(0)$ & $0(0)$ \\
\hline CR & $0(0)$ & $0(0)$ & $2(25)$ & $6(75)$ & $0(0)$ & $0(0)$ & $0(0)$ \\
\hline POI & $0(0)$ & $0(0)$ & $3(37)$ & $5(62)$ & $0(0)$ & $0(0)$ & $0(0)$ \\
\hline RDI & $0(0)$ & $1(12)$ & $0(0)$ & $3(37)$ & $3(37)$ & $1(12)$ & $0(0)$ \\
\hline PSI & $0(0)$ & $1(12)$ & $1(12)$ & $6(75)$ & $0(0)$ & $0(0)$ & $0(0)$ \\
\hline
\end{tabular}

\begin{tabular}{|c|c|c|c|c|c|c|c|}
\hline & \multicolumn{7}{|c|}{ Developmental Dyslexia Classification $-f(\%)$} \\
\hline & VS & SP & HA & AV & LA & BL & $\mathbf{E L}$ \\
\hline VIQ & $1(7)$ & $0(0)$ & $10(76)$ & $0(0)$ & $2(15)$ & $0(0)$ & $0(0)$ \\
\hline PIQ & $0(0)$ & $1(7)$ & $5(38)$ & $4(30)$ & $2(15)$ & $1(7)$ & $0(0)$ \\
\hline TIQ & $0(0)$ & $1(7)$ & $3(23)$ & $9(69)$ & $0(0)$ & $0(0)$ & $0(0)$ \\
\hline CR & $0(0)$ & $1(7)$ & $1(7)$ & $10(76)$ & $1(7)$ & $0(0)$ & $0(0)$ \\
\hline POI & $0(0)$ & $2(15)$ & $4(30)$ & $4(30)$ & $3(23)$ & $0(0)$ & $0(0)$ \\
\hline RDI & $0(0)$ & $0(0)$ & $1(7)$ & $9(69)$ & $2(15)$ & $1(7)$ & $0(0)$ \\
\hline \multirow[t]{3}{*}{ PSI } & $0(0)$ & $1(7)$ & $2(15)$ & $8(61)$ & $2(15)$ & $0(0)$ & $0(0)$ \\
\hline & \multicolumn{7}{|c|}{ NCG Classification $-f(\%)$} \\
\hline & VS & SP & HA & $\mathbf{A V}$ & LA & BL & EL \\
\hline VIQ & $4(33)$ & $2(16)$ & $1(8)$ & $2(16)$ & $3(25)$ & $0(0)$ & $0(0)$ \\
\hline PIQ & $3(25)$ & $2(16)$ & $4(33)$ & $1(8)$ & $2(16)$ & $0(0)$ & $0(0)$ \\
\hline TIQ & $4(33)$ & $1(8)$ & $4(33)$ & $2(16)$ & $1(8)$ & $0(0)$ & $0(0)$ \\
\hline $\mathrm{CR}$ & $4(33)$ & $2(16)$ & $2(16)$ & $2(16)$ & $2(16)$ & $0(0)$ & $0(0)$ \\
\hline POI & $2(16)$ & $2(16)$ & $2(16)$ & $4(33)$ & $2(16)$ & $0(0)$ & $0(0)$ \\
\hline RDI & $3(25)$ & $2(16)$ & $2(16)$ & $3(25)$ & $1(8)$ & $1(8)$ & $0(0)$ \\
\hline PSI & $3(25)$ & $3(25)$ & $2(16)$ & $4(33)$ & $0(0)$ & $0(0)$ & $0(0)$ \\
\hline
\end{tabular}

Abbreviations: M: Mean; SD: Standard Deviation; $f$ Frequency; \%: percentage; VS: Very Superior; SP: Superior; HA: High Average; AV: Average; LA: Low Average; BL: Borderline; EL: Extremely Low; ${ }^{a}$ : Kruskal-Wallis; * : significant difference at the $\mathrm{p} \leq 0,05$ level; ${ }^{* *}$ : significant difference at the $\mathrm{p} \leq 0,01$ level. 
Table 2.

Performances and comparisons among groups obtained through tests selected to assess Attention, Executive Functions and Memory

\begin{tabular}{|c|c|c|c|c|c|c|c|}
\hline \multirow{3}{*}{ Instruments } & \multicolumn{6}{|c|}{ Groups } & \multirow{4}{*}{ Mann-Whitney } \\
\hline & \multicolumn{2}{|c|}{ DD } & \multicolumn{2}{|c|}{$\begin{array}{c}\text { DYSLEXIA } \\
\text { Gross Scores }\end{array}$} & \multicolumn{2}{|c|}{ NCG } & \\
\hline & & & & & & & \\
\hline & $\mathbf{M}$ & SD & $\mathbf{M}$ & SD & $\mathbf{M}$ & SD & \\
\hline \multicolumn{8}{|l|}{ Attention } \\
\hline Coding $a, *$ & 34.12 & 6.87 & 32.61 & 7.98 & 43.00 & 9.95 & $\begin{array}{c}\mathrm{NCG}>\mathrm{DD} * \\
\mathrm{NCG}>\text { DYSLEXIA } * *\end{array}$ \\
\hline Symbol Search a,* & 19.12 & 3.72 & 18.76 & 4.58 & 24.41 & 6.25 & $\begin{array}{c}\mathrm{NCG}>\mathrm{DD} * \\
\mathrm{NCG}>\text { DYSLEXIA* }\end{array}$ \\
\hline \multicolumn{8}{|l|}{ Executive Functions } \\
\hline $\begin{array}{l}\text { Digit Span (backward } \\
\text { order) }\end{array}$ & 3.28 & 1.38 & 3.84 & 2.51 & 4.37 & 2.44 & - \\
\hline Arithmetic & 13.12 & 1.80 & 13.38 & 2.06 & 14.33 & 1.96 & - \\
\hline PRBC & 37.62 & 1.76 & 35.69 & 3.94 & 37.00 & 5.16 & NCG > DYSLEXIA* \\
\hline \multicolumn{8}{|l|}{ Stroop Test } \\
\hline Time (sec) - Card $1 \mathrm{a}, *$ & 25.25 & 4.83 & 30.07 & 7.17 & 22.75 & 4.61 & NCG $>$ DYSLEXIA** \\
\hline No. errors & 0.25 & 0.46 & 0.15 & 0.55 & 0.00 & 0.00 & - \\
\hline Time (sec) - Card 2 & 35.50 & 7.23 & 33.69 & 9.47 & 32.91 & 9.55 & - \\
\hline No. errors & 0.50 & 1.06 & 0.07 & 0.27 & 0.75 & 1.42 & - \\
\hline Time (sec) - Card 3 & 41.75 & 13.24 & 45.46 & 31.37 & 40.66 & 14.92 & - \\
\hline No. errors & 0.87 & 1.12 & 0.23 & 0.43 & 0.83 & 1.40 & - \\
\hline \multicolumn{8}{|l|}{ WCST } \\
\hline No. categories completed & 4.37 & 1.99 & 4.15 & 1.81 & 5.08 & 1.31 & - \\
\hline No. tests (max. 128) & 114.12 & 17.85 & 120.69 & 17.84 & 115.50 & 17.44 & - \\
\hline Persistent Errors (max 128) & 29.00 & 24.61 & 35.00 & 22.82 & 22.33 & 13.81 & - \\
\hline Total correct responses & 71.12 & 15.99 & 62.23 & 16.58 & 73.33 & 14.81 & - \\
\hline Total errors & 43.00 & 25.19 & 58.46 & 25.41 & 42.25 & 21.83 & - \\
\hline $\begin{array}{l}\text { Failure to maintaining the } \\
\text { context }\end{array}$ & 1.00 & 1.41 & 0.46 & 0.87 & 1.58 & 1.24 & NCG > DYSLEXIA* \\
\hline \multicolumn{8}{|l|}{ Memory } \\
\hline Digit a,** & 3.28 & 1.38 & 3.84 & 2.51 & 4.37 & 2.44 & $\begin{array}{c}\text { NCG }>\text { DD } * * \\
\text { NCG }>\text { DYSLEXIA } * *\end{array}$ \\
\hline \multicolumn{8}{|l|}{ RCFT } \\
\hline Copy & 35.00 & 29.27 & 27.30 & 26.81 & 34.16 & 28.02 & - \\
\hline Memory & 26.25 & 17.87 & 25.53 & 24.45 & 35.00 & 36.36 & - \\
\hline Time copy & 44.62 & 22.89 & 35.15 & 28.18 & 37.91 & 20.27 & - \\
\hline Time memory & 35.87 & 23.55 & 22.25 & 11.02 & 31.08 & 19.89 & - \\
\hline
\end{tabular}

Abbreviations: M: Mean; SD: Standard Deviation; ${ }^{a}$ : Kruskal-Wallis; $*$ : significant difference at the $\mathrm{p} \leq 0,05$ level; ${ }^{* *}$ : significant difference at the $\mathrm{p} \leq 0,01$ level. 
Table 3.

Performances and comparisons among groups obtained through tests selected for assessment of School Skills

\begin{tabular}{|c|c|c|c|c|c|c|c|}
\hline \multirow{4}{*}{ Instruments } & \multicolumn{6}{|c|}{ Groups } & \multirow{4}{*}{ Mann-Whitney } \\
\hline & \multicolumn{2}{|c|}{ DD } & \multirow{2}{*}{\multicolumn{2}{|c|}{$\begin{array}{c}\text { DYSLEXIA } \\
\text { Gross Scores }\end{array}$}} & \multicolumn{2}{|c|}{ NCG } & \\
\hline & & & & & & & \\
\hline & $\mathbf{A}$ & SD & $\mathbf{A}$ & SD & $\mathbf{A}$ & SD & \\
\hline \multicolumn{8}{|l|}{ APT } \\
\hline Reading $\mathrm{a}, * * *$ & 63.25 & 6.79 & 44.76 & 21.17 & 66.66 & 2.22 & $\begin{array}{c}\text { NCG }>\text { DYSLEXIA } * * * \\
\text { DD }>\text { DYSLEXIA** }\end{array}$ \\
\hline Writing a,** & 24.12 & 5.16 & 13.92 & 8.28 & 25.41 & 5.46 & $\begin{array}{c}\text { NCG }>\text { DYSLEXIA } * * * \\
\text { DD }>\text { DYSLEXIA** }\end{array}$ \\
\hline Arithmetic & 13.37 & 5.18 & 11.23 & 4.95 & 13.66 & 3.65 & - \\
\hline Total a,** & 100.87 & 14.20 & 69.92 & 30.71 & 105.75 & 8.94 & $\begin{array}{c}\text { NCG }>\text { DYSLEXIA *** } \\
\text { DD }>\text { DYSLEXIA*** }\end{array}$ \\
\hline Arithmetic Test & 41.12 & 14.56 & 35.53 & 12.83 & 43,08 & 10,78 & - \\
\hline
\end{tabular}

Abbreviations: A: Average; SD: Standard Deviation; ${ }^{a}:$ Kruskal-Wallis; ${ }^{*}$ : Significant difference at the $\mathrm{p} \leq 0,05$ level; ** : significant difference at the $\mathrm{p} \leq 0,01$ level; *** : significant difference at the $\mathrm{p} \leq 0,001$ level.

al., 2010). Regarding dyslexia, studies have speculated that this would be due to deficits in the functioning of the parietal zones of the right hemisphere associated (Peyrin et al., 2012), or even the left hemisphere in the temporal zones, and thus, the theory of phonological processing would be even more supported (Landerl \& Willburger, 2010). In dyscalculia there is a frequent observation that hypofunctioning in the right parietal lobe (zone related to numeric and quantity sense) would explain both the disorder and the attention deficit (Furman \& Rubinsten, 2012; Rubinsten \& Henik, 2009). No national and international studies have been found that investigated the comparison of these two disorders in this ability. These results indicated that there were no differences between such groups.

Regarding the EF, it was verified that the group with dyscalculia did not differ from the non-case group in any of the tests. The group with dyslexia differed from the non-case group in pseudoword repetition, in the color-naming time of the Stroop test and in the "failure to maintaining the context" of the WCST test. However, broader deficits were expected in both disorders, according to the literature, and in most of the subtests that were within the assessment protocol of this ability (as in Digit Span and Arithmetic) (Menghini et al., 2010). Researches indicate that the prefrontal cortex would be the most related to EF (Stuss, 2011). Hypothetically, it can be said that impairments in Specific Learning Disorders in such a brain zone would be expected, as well as in EF, since dysfunctions in posterior zones are verified (as shown in the previous paragraph). According to Luria (1981), for the proper functioning of frontal zones it is necessary that zones after it are intact, which is not the case in these cases. When the diagnostic groups were compared in the EF, no significant differences between them were again found. This result was compatible with the study by Landerl et al. (2009), which also indicated that in digit repetition the groups did not differentiate. On the other hand, Wang et al. (2012) pointed out differences in the Stroop test, in boards involving numbers and letters, which did not occur here in relation to the words (stimulus that composed the test structure used here).

In the memory assessment, there was lower performance of the group with dyscalculia and dyslexia in short-term auditory memory when compared to the non-case group. Studies indicate that this result is expected when these groups are compared to children without difficulties (Attout et al., 2015; Bogaerts et al., 2014). In short-term visual memory, no differences were found among any of the groups. This was not expected, according to the literature, especially when nosological groups were compared to children without learning difficulties (Bacon \& Handley, 2014; Szucs, Devine, Soltesz, \& Gabriel, 2013).

Theoretically, there are some postulates affirming that attention and executive abilities act collaterally and / or even are integral mechanisms of the functioning 
and maintenance of memory, both short and long term (Bull, Espy, \& Wiebe, 2008). As both skills are at a disadvantage in Specific Learning Disorders, then, consequently in these groups, impairments in different types of memory must be found. This statement corroborates, to a certain extent, the data found here, and which pointed out lowered performances in attention and in some executive aspects. Studies aiming at comparing both disorders, which are discussed here and regarding memory, were not found, but it was found that both disorders did not differ statistically.

Unfortunately, studies aiming at comparing neuropsychological abilities of developmental dyslexia and dyscalculia were found to be scarce in the literature. In any case, what could explain the fact that they did not differ in any of the skills selected here to compose the neuropsychological profile (intelligence, attention, executive functions and memory)? Some hypotheses have been elaborated: (a) the functional impairments in posterior zones and characteristic of each disorder would alter the assessed abilities in the same way, in general, independently of the stimuli used in the instruments and even in the use of these skills in daily life (both linguistic and mathematical); (b) the disorders are explained by impairments in very close processing brain areas, and thus, they would show a similar neuropsychological profile in skills investigated here. These areas would involve left perisylvian zones, left occipitotemporal fusiform gyrus, fronto-parietal zones (Ramus et al., 2013, Rosenberg-Lee et al., 2015, Vicario, Rappo, Pepi, Pavan \& Martino, 2012).

According to our findings, what differentiated both situations were topographically the school difficulties involved. Among them (writing, reading and arithmetic), there was a statistically significant lower performance in writing and reading of the group with dyslexia when compared to the group with dyscalculia, this also happened when the group with dyslexia was compared to the non-case group. Somehow, such results were expected, since dyslexia mainly involves written language impairments (APA, 2013; Ramus et al., 2013). So, when the tasks were involving specific reading and writing school skills, unlike when the neuropsychological abilities with linguistic stimuli were assessed, differences between the disorders were observed.

However, the school skill in arithmetic of the group with dyscalculia differing from the group with dyslexia and non-case group was also expected, with a statistically significant lower performance, but did not happen. According to the DSM-V (APA, 2013), a minimum of 1.5 standard deviation below the mean can be expected, but it is also justified that, although the use of psychometric instruments is performed to guide the diagnosis, any significant performance measure below the range may be considered arbitrary and clinical assessment should prevail. In this case, the means obtained by the group with dyscalculia were smaller than the group with dyslexia, but not enough to indicate statistical differences.

Interestingly, the group with dyslexia had lower mean scores in arithmetic than the group with dyscalculia. Studies in literature indicating the same results were not found. In this study, the children of the group with dyslexia did not have comorbidity with dyscalculia and showed inferior performance (although not statically significant) than those who only had this last situation. Thus, some hypotheses are raised for these results: (a) the greater impairment in neuropsychological abilities of executive functions of the group with dyslexia, when compared to the non-case group in relation to the one with dyscalculia, as seen here, would favor greater impairments in arithmetic (Geary et al., 2012). (b) the linguistic impairments of dyslexia would favor inferior performance in arithmetic skills, as research has also shown (Träff \& Passolunghi, 2015), even lower than those seen in dyscalculia.

In any case, this research fulfilled its objective of comparing the neuropsychological and school profiles of children with dyscalculia and developmental dyslexia, in order to verify if the performances of both groups differed in more detail, in addition to the diagnostic criteria already established. The results showed that the groups did not differentiate as to the neuropsychological abilities investigated (intelligence, attention, executive functions and memory), but only in reading and writing school skills, with the group with dyslexia showing inferior performances. The hypothesis raised was thus confirmed, and only partially, in relation to these skills.

Reduced performances in neuropsychological abilities involving mathematical content (for example, in WISC-III Digit Span and Arithmetic subtests) in the group with dyscalculia compared to the group with dyslexia, and lower performances in neuropsychological abilities involving reading (for example, in the Pseudoword Repetition Test for Brazilian Children and Stroop Test) in the group with dyslexia when compared to the group with dyscalculia. It was also expected lower performance in the APT Arithmetic subtest and in the Arithmetic test in the group with dyscalculia in relation to the one with dyslexia. 
These findings are important for health, education and research. For the first area, it could be observed that Specific Learning Disorders could have a generalized impact on the functioning of the investigated neuropsychological abilities (except in intelligence), demonstrating that they need strong interventions at the multi / interdisciplinary level.

For the education area, these results become relevant because they mainly demonstrate that the condition of dyscalculia may go unnoticed in the age groups and grades studied. According to the data found, the differences in the instruments that assessed the school skills in arithmetic were subtle among children without school difficulties and those with this condition. It should be emphasized, therefore, that attention to such subtleties in educational processes must be made for an early diagnosis. On the other hand, children with dyslexia would already be more easily identified (there were discrepant results in reading and writing skills when compared to the group without school difficulties).

As for the research in the field, the data point out to more careful analysis in evaluation processes. The first interesting point to note is regarding the historically used performance discrepancies between Intellectual Quotient (IQ) and performance in school tests in the performance of the diagnoses of specific learning disorders (APA, 2013). As seen here, there was no such difference mainly between the groups with dyscalculia and without school difficulties. Relying only on these data, without a qualitative analysis of clinical basis, should not be the only way for a consistent assessment. A second point of analysis to be surveyed is also suggested, from this point of analysis: criterion validity studies involving these conditions in neuropsychological tests and assessment of school skills. It was possible to identify that none of the instruments used in this research, which are mostly very frequently used in the Brazilian neuropsychological assessment, had these studies. Further research on these psychometric procedures is advised.

Therefore, the limitations found in this study are mainly related to the number of individuals investigated, which made it impossible to analyze the effect of the variables gender and grade. In future studies, it is expected that there will also be an increase in the number of instruments used to investigate the skills described here and that these have greater ecological validity. In addition, it is proposed that the neuropsychological abilities that compose the profile investigated here should be expanded, especially with linguistic skills (such as phonological processing) and in a longitudinal way (as already suggested by Silva, Moura, Wood \& Haase, 2015), so that differences between dyscalculia and dyslexia are even better delineated.

\section{References}

American Psychiatric Association (APA). (2013). Diagnostic and statistical manual of mental disorders: DSM-V. Washington, DC: American Psychiatric Association.

Ashkenazi, S., Rubinsten, O., \& Henik, A. (2009). Attention, automaticity, and developmental dyscalculia. Neuropsychology, 23(4), 535-540. doi: 10.1037/ a0015347

Attout, L., Salmon, E., \& Majerus, S. (2015). Working Memory for Serial Order Is Dysfunctional in Adults With a History of Developmental Dyscalculia: Evidence From Behavioral and Neuroimaging Data. Developmental neuropsychology, 40(4), 230-247. doi: 10.1080/87565641.2015.1036993

Bacon, A. M., \& Handley, S. J. (2014). Reasoning and Dyslexia: is Visual Memory a Compensatory Resource?. Dyslexia, 20(4), 330-345. doi: 10.1002/ dys. 1483

Boets, B., \& De Smedt, B. (2010). Single-digit arithmetic in children with dyslexia. Dyslexia, 16(2), 183-191. doi: 10.1002/dys.403

Bogaerts, L., Szmalec, A., Page, M. P. A., \& Duyck, W. (2014). Linking memory and language: insights from novel word learning and dyslexia. International Workshop on Learning and Memory Consolidation, Abstracts, San Sebastian, Spain. Recuperado de:

https:/ / www.researchgate.net/publication/279265591_Linking_memory_and_language_insights_from_novel_word_learning_and_ dyslexia

Bull, R., Espy, K. A., \& Wiebe, S. A. (2008). Shortterm memory, working memory, and executive functioning in preschoolers: Longitudinal predictors of mathematical achievementatage7years. Developmental neuropsychology, 33(3), 205-228. doi: 10.1080/8756564080198231

Caldonazzo, A., Salgado, C., Capellini, S., \& Ciasca, S. (2006). Desempenho na resolução de problemas envolvendo o conceito aditivo em sujeitos 
com dislexia do desenvolvimento. Psicopedagogia, 23(71), 116-123. Recuperado de: http://www. revistapsicopedagogia.com.br/detalhes/394/ desempenho-na-resolucao-de-problemas-envolvendo-o-conceito-aditivo-em-sujeitos-com-dislexia-do-desenvolvimento

Capovilla, A. G. S., Montiel, J. M., \& Capovilla, F. C. (2007). Prova de Aritmética. In A. G. S. Capovilla, \& F. C. Capovilla. Teoria e Pesquisa em avaliação neuropsicológica (pp. 45-60). São Paulo: Memnon.

Cunha, J. A. (2005). Adaptação e padronização brasileira do Teste Wisconsin de Classificação de Cartas - WCST. São Paulo: Casa do Psicólogo.

Duncan, M. T. (2006). Obtenção de dados normativos para desempenho no teste de Stroop num grupo de estudantes do ensino fundamental em Niterói. Jornal Brasileiro de Psiquiatria, 55(1), 42-48. doi: 10.1590/50047-20852006000100006

Figueiredo, V. L. M. (2002). Adaptação e padronização brasileira da escala de inteligência Wechsler para crianças, terceira edição - WISC-III. São Paulo: Casa do Psicólogo.

Frijeters, J. C., Lovett, M. W., Steinbach, K. A., Wolf, M., Sevcik, R. A., \& Morris, R.D. (2011). Neurocognitive predictors of reading outcomes for children with reading disabilities. Journal of Learning Disabilities, 44(2), 150-166. doi: 10.1177/0022219410391185

Furman, T., \& Rubinsten, O. (2012). Symbolic and non symbolic numerical representation in adults with and without developmental dyscalculia. Behavioral and Brain Functions, 8(1), 55. doi: 10.1186/1744-9081-8-55

Geary, D. C., Hoard, M. K., Nugent, L., \& Bailey, D. H. (2012). Mathematical cognition deficits in children with learning disabilities and persistent low achievement: A five-year prospective study. Journal of Educational Psychology, 104(1), 206-223. doi: 10.1037/a0025398

Jednoróg, K., Marchewka, A., Tacikowski, P., Heim, S., \& Grabowska, A. (2011). Electrophysiological evidence for the magnocellular-dorsal pathway deficit in dyslexia. Developmental science, 14(4), 873-880. doi: 10.1111/j.1467-7687.2011.01037.x

Landerl, K., \& Willburger, E. (2010). Temporal processing, attention, and learning disorders. Learning and individual differences, 20(5), 393-401. doi: 10.1016/j. lindif.2010.03.008

Lima, R. F., Azoni, C. A. S., \& Ciasca, S. M. (2013). Attentional and executive deficits in Brazilian children with developmental dyslexia. Psychology, 4(10A), 1-6. doi: 10.4236/psych.2013.410A001

Luria, A. R. (1981). Fundamentos de neuropsicologia. São Paulo: Edusp.

McCloskey, M., Caramazza, A., \& Basili, A. (1985). Cognitive mechanisms in number processing and calculation: Evidence from dyscalculia. Brain and cognition, 4(2), 171-196. doi: 10.1016/0278-2626(85)90069-7

Menghini, D., Finzi, A., Benassi, M., Bolzani, R., Facoetti, A., Giovagnoli, S., Rufinno, M., \& Vicari, S. (2010). Different underlying neurocognitive deficits in developmental dyslexia: a comparative study. Neuropsychologia, 48(4), 863-872. doi: 10.1016/j. neuropsychologia.2009.11.003

Moura, O., Simões, M. R., \& Pereira, M. (2014). WISC-III Cognitive Profiles in Children with Developmental Dyslexia: Specific Cognitive Disability and Diagnostic Utility. Dyslexia, 20(1), 19-37. doi: 10.1002/dys.1468

Nicolson, R. I., \& Fawcett, A. J. (2011). Dyslexia, dysgraphia, procedural learning and the cerebellum. Cortex, 47 (1), 117-127. doi: 10.1016/j. cortex.2009.08.016

O’hare, A. E., Brown, J. K., \& Aitken, K. (1991). Dyscalculia in children. Developmental Medicine \& Child Neurology, 33(4), 356-361. doi: 10.1111/j.14698749.1991.tb14888x

Oliveira, M., \& Rigoni, M. (2010). Figuras Complexas de Rey - Teste de cópia e de reproducão de memória de figuras geométricas complexas. Adaptação brasileira. São Paulo: Casa do Psicólogo.

Peyrin, C., Lallier, M., Demonet, J. F., Pernet, C., Baciu, M., Le Bas, J. F., \&Valdois, S. (2012). Neural dissociation of phonological and visual attention span disorders in developmental dyslexia: FMRI evidence from two case reports. Brain and language, 120(3), 381-394. doi: 10.1016/j.bandl.2011.12.015

Ramus, F., Marshall, C. R., Rosen, S., \& van der Lely, H. K. (2013). Phonological deficits in specific language impairment and developmental dyslexia: 
towards a multidimensional model. Brain, 136(2), 630-645. doi: 10.1093/brain/aws356

Rosenberg-Lee, M., Ashkenazi, S., Chen, T., Young, C. B., Geary, D. C., \& Menon, V. (2015). Brain hyperconnectivity and operation-specific deficits during arithmetic problem solving in children with developmental dyscalculia. Developmental science, 18(3), 351-372. doi: 10.1111/desc.12216

Rubinsten, O., \& Henik, A. (2009). Developmental dyscalculia: heterogeneity might not mean different mechanisms. Trends in cognitive sciences, 13(2), 92-99. doi: 10.1016/j.tics.2008.11.002

Santos, F. H., \& Bueno, O. F. A. (2003). Validation of the Brazilian Children's Test of Pseudoword Repetition in Portuguese speakers aged 4 to 10 years. Brazilian Journal of Medical and Biological Research, 36(11), 1533-1547. doi: 10.1590/ S0100-879x2003001100012

Seabra, A. G., Dias, N. M., \& Macedo, E. C. (2010). Desenvolvimento das habilidades aritméticas e composição fatorial da Prova de Aritmética em estudantes do Ensino Fundamental. Interamerican Journal of Psychology, 44(3), 481-488. Recuperado de: http://www.redalyc.org/comocitar.oa?id $=28420658010$

Shalev, R. S., Manor, O., \& Gross-Tsur, V. (2005). Developmental dyscalculia: a prospective sixyear follow-up. Developmental Medicine \& Child Neurology, 47(02), 121-125. doi: 10.1111/j.14698749.2005.tb01100.x

Silva, J. B. L., Moura, R. J. D., Wood, G., \& Haase, V. G. (2015). Processamento fonológico e desempenho em aritmética: uma revisão da relevância para as dificuldades de aprendizagem. Temas em Psicologia, 23(1), 157-173. doi: 10.9788/TP2015.1-11

Simmons, F. R., \& Singleton, C. (2009). The mathematical strengths and weaknesses of children with dyslexia. Journal of Research in Special Educational Needs, 9(3), 154-163. doi: 10.1111/j.1471-3802.2009.01128.x

Stanescu-Cosson, R., Pinel, P., van de Moortele, P. F., Le Bihan, D., Cohen, L., \& Dehaene, S.
(2000). Understanding dissociations in dyscalculia. Brain,123(11), 2240-2255. doi: 10.1093/ brain/123.11.2240

Stein, L.M. (1994). TDE: Teste de Desempenho Escolar. São Paulo: Casa do Psicólogo.

Stuss, D. T. (2011). Functions of the frontal lobes: relation to executive functions. Journal of the International Neuropsychological Society, 17(05), 759-765. doi: 10.1017/S1355617722000695

Szucs, D., Devine, A., Soltesz, F., Nobes, A., \& Gabriel, F. (2013). Developmental dyscalculia is related to visuo-spatial memory and inhibition impairment. Cortex, 49(10), 2674-2688. doi: 10.1016/j. cortex.2013.06.007

Träff, U., \& Passolunghi, M. C. (2015). Mathematical skills in children with dyslexia. Learning and Individual Differences, 40, 108-114. doi: 10.1016/j. lindif.2015.03.024

Vicario, C. M., Rappo, G., Pepi, A., Pavan, A., \& Martino, D. (2012). Temporal abnormalities in children with developmental dyscalculia. Developmental Neuropsychology, 37(7), 636-652. doi: 10.1080/87565641.2012.702827

Wang, L. C., Tasi, H. J., \& Yang, H. M. (2012). Cognitive inhibition in students with and without dyslexia and dyscalculia. Research in developmental disabilities, 33(5), 1453-1461. doi: 10.1016/j.ridd.2012.03.019

Wilson, A. J., \& Dehaene, S. (2007). Number sense and developmental dyscalculia: In D. Coch, G. Dawson, \& K. Fisher (Eds.). Human behavior, learning, and the developing brain: Atypical development (pp.212238). New York: Guilford.

Ziegler, J. C., Pech-Georgel, C., Dufau, S., \& Grainger, J. (2010). Rapid processing of letters, digits and symbols: what purely visual-attentional deficit in developmental dyslexia? Developmental Science, 13(4), F8-F14. doi:10.1111/j.1467-7697.2010.00983.x

Recebido em: 04/07/2017 Reformulado em: 27/06/2018; 14/09/2018 Aprovado em: 07/11/2018 
About the authors:

Magda Solange Vanzo Pestun: Ph.D. in Medical Sciences, field of Biomedical Sciences - Faculty of Medical Sciences- Universidade Estadual de Campinas (FCM/UNICAMP). Associate professor C at Universidade Estadual de Londrina (UEL). Acts in the area of Specific Learning Disorders.

ORCID: 0000-0002-9112-744X

E-mail:pestun@sercomtel.com.br

Rauni Jandé Roama-Alves: Ph.D. in Psychology (Psychological Assessment subarea) from the Pontifícia Universidade Católica de Campinas (PUC-Campinas). Associate Professor in the area of Psychological Assessment at the Universidade Federal de Rondonópolis (UFR). Specialist in Neuropsychology Applied to Child Neurology and in Improvement in Psychopedagogy Applied to Child Neurology, both from Universidade Estadual de Campinas (UNICAMP).

ORCID: 0000-0002-1982-1488

E-mail: rauniroama@gmail.com

Sylvia Maria Ciasca: Ph.D. in Neuroscience from the Universidade Estadual de Campinas (UNICAMP), Full Professor in Child Neurology. Associate Professor III at UNICAMP. Member of the Ibero-American Academy of Pediatric Neurology (AINP), Brazilian Association of Neurology, Child Psychiatry and Related Professions (ABENEPI), and Brazilian Academy of Neurology. Coordinator of the Laboratory of Learning and Attention Disorders (DISAPRE), Faculty of Medical Sciences /UNICAMP.

ORCID: 0000-0002-8841-1319

E-mail: sciasca2015@gmail.com

Contact:

Rua João Huss, 115, apt.1504

Londrina-PR, Brasil

CEP: 86050-490 
